\title{
To the question on the factors of formation of the sands density and their potential accounting by cone penetration test
}

\author{
Pavel Kashperyuk ${ }^{1, *}$, Kristina Nikitina ${ }^{1}$, and Aleksandr Yulin $^{2}$ \\ ${ }^{1}$ Moscow state university of civil engineering, Yaroslavskoye shosse, 26, Moscow, Russia, 129337 \\ ${ }^{2}$ Chief engineer of LLC NPF "SIVS", 117393, 45A, street of Architect Vlasova, Moscow, Russia
}

\begin{abstract}
Undisturbed sampling of sands from boreholes is difficult. It is important to find methods for determining the sands density in-situ, in particular, by cone penetration test. According to the results of cone penetration test can be determined only the categories of relative density of sands depending on their size distribution and probing depth. Based on an extensive literary material and long-term studies of the authors were considered a number of factors, which form the natural density of sands with different particle size distribution and genesis. For improving the accuracy, it is necessary to consider not only the particle size distribution, but also morphological features of grains, primarily depending on the genesis. The most versatile and effective indicator of the morphological features of grains is generalized morphological index $\lambda$ (by A.D. Potapov). Taking into account that the empirical formula for quantitative assessment of the sands density by cone resistance (by L.G. Mariupolskiy), in our opinion, applicable only for average-size sands without considering of their uniformity, genesis and generalized morphological index, content of silt and clay fraction, water saturation and presence of cohesion-hardening, we offer new correlations between dry soils density and cone resistance for different genetic types of sand.
\end{abstract}

For many engineering surveys it is a problem to determine the value of sands density by practical consideration. This problem becomes unsolvable using only direct methods of borehole sampling with increasing depth and changes in water saturation of sands.

Current laboratory methods for determining the density of sandy soils due to their complexity and often - the impossibility of undisturbed sampling, with the sufficient reliability do not allow to estimate their main physical parameters, in particular, values of densities.

An analysis of archival materials of engineering surveys in Moscow has shown that more than $90 \%$ of laboratory determinations of physical properties of sands contains no direct measurements of density, limited the definition of particle size distribution, water

\footnotetext{
*Corresponding author: npf-sivs@yandex.ru
} 
content, solid particles density $\left(\rho_{\mathrm{s}}\right)$, maximum and minimum dry density $\left(\rho_{\mathrm{dmax}}\right.$ И $\left.\rho_{\mathrm{dmin}}\right)$ and friction angle.

In such cases, as a rule, the density of sand can be obtained by reverse calculation by setting the value of the void ratio (e) after the provisional qualitative assessment the studied density of sand and calculating its degree of water-saturation. The qualitative assessment (category) of the relative density of sand associating with the cone resistance $\left(\mathrm{q}_{\mathrm{s}}\right)$ can be carried out on the table I.1, SP 47.13330.2012 [1].

However, using the specified table, to set the value of the void ratio for the sample of sand with the value $\mathrm{q}_{\mathrm{s}}$, for example (for fine sand of medium density) equal to $8 \mathrm{MPa}$, with the change of its value $\mathrm{q}_{\mathrm{s}}$ in a range from $4 \mathrm{MPa}$ to $12 \mathrm{MPa}$, and void ratio from 0.75 to 0.60 , the direct interpolation method is not possible, as for the ranges of variations the above values of e and $\mathrm{q}_{\mathrm{s}}$, there is no direct correlation, or at least its presence in each case requires proof. If the medium density sand with interpolation similarity linear dependence between e and $\mathrm{q}_{\mathrm{s}}$ can be assumed, for loose and dense sand such a device is impossible because of lack in the table and in practice (in-situ) determinations of void ratio (e) extreme ( $\max$ and $\mathrm{min}$ ) values of these indicators.

According to numerous publications, current research of properties of sandy soils shows that in addition to the particle size distribution of a significant impact on the density have age, genesis, mineral composition, natural water content, depth, degree of rounding of the particles, the surface shape of the particles, the presence of cover ("shirts"), the roughness of the grains, and the spatial arrangement, etc. [2, 3, 4, 5, 6, and 7]. It is known that in previously examined table I.1, SP 47.13330.2012 [1], none of the above factors affecting the sands density, except the particle size distribution and depth of probing, is not considered.

During penetration testing some researchers have noted a number of factors influence the value of cone resistance $\left(\mathrm{q}_{\mathrm{s}}\right)$ and the sleeve friction $\left(\mathrm{f}_{\mathrm{s}}\right)$. So, Yu.G. Trofimenkov and L.N. Vorobkov [8] noted the impact of the roughness of grains surface (R), the uniformity coefficient $\left(\mathrm{C}_{\mathrm{u}}\right)$ and even the presence of small amount of dust particles $\left(\sum \mathrm{d}<0.05 \mathrm{~mm}\right)$, which can cause substantial deviations of cone resistance from the mean values, listed in the table I.1, SP 47.13330.2012 [1].

Research of sands by V.I. Kashirskiy [9] made it possible to establish a connection between the varieties of sandy soils and their performance of cone resistance and friction ratio $\left(\mathrm{R}_{\mathrm{f}}\right)$. Thus, for each studied variety of sands (from gravel to silty) change in the value of cone resistance $\left(\mathrm{q}_{\mathrm{s}}\right)$ from $0.5 \mathrm{MPa}$ to $40.0 \mathrm{MPa}$ and friction ratio $\left(\mathrm{R}_{\mathrm{f}}\right)$ from $0.3 \%$ to $4.0 \%$ he explains by changing of their density and quantitative content in the sands of silty clay fraction. Indeed, porosity decreases with increasing of grain-size and density, what leads to increasing of cone resistance. With decreasing the grain-size of sand and increasing the density increases the number of contacts of the sand grains with a friction-coupling surface, leading to an increase in friction ratio $\left(\mathrm{R}_{\mathrm{f}}\right)$.

P.L. Ivanov and L.V. Schultz [4] studied the influence of the morphology of the sand grains on the value of the min and max density based on an evaluation of roundness $(\alpha)$ and sphericity $(\beta)$ of grains. They found (Fig.1) that with an increase in the treatment of the grains surface extreme values of the void ratio is reduced, so sands fit more tightly, which complicates the penetration of cone into the soil and leads to an increasing values of $\mathrm{q}_{\mathrm{s}}$ and $\mathrm{R}_{\mathrm{f}}$.

The influence of the morphological characteristics of the sands on their properties were particularly studied by I.V. Dudler and A.D. Potapov [3]. A.D. Potapov suggested using the generalized morphological index $(\lambda)$, which takes into account not only the roundness and sphericity of grains, but also the roughness of their surfaces. He identified six categories of the treatment of sands grains, and the study of sands of various origins allowed establishing its influence on morphological characteristics of the sands. According to A.D. Potapov [5, 
10], the treatment of grains increases in the following sequence: volcanic $\rightarrow$ aeolian $\rightarrow$ fluvioglacial $\rightarrow$ alluvial $\rightarrow$ limnoglacial $\rightarrow$ marine.

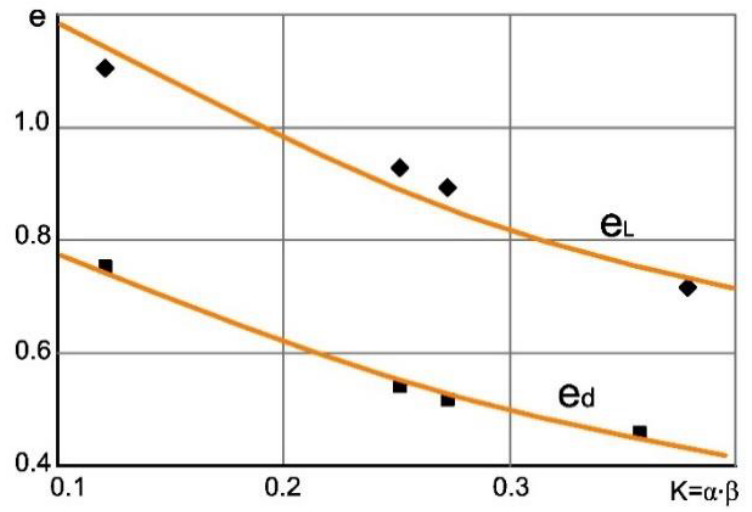

Fig.1. Influence of the particles (grains) shape on values of void ratio (according to P.L. Ivanov, L.V. Shulc, [4]). K - form coefficient (generalized index of roundness and sphericity of grains).

Our study (according to the materials of long-term surveys LLC NPF "SIVS", LLC "Investroy", LLC "IGC" in Moscow and the near suburbs) of the influence of grains morphology in alluvial sands (fine and medium) on their density showed that with increasing of roundness, sphericity, and the generalized morphological index, increases the density and decreases porosity (Fig. 2). At the same time, with angular and very nonspherical grains the average value of the void ratio in a very loose state is 0.95 , and in a very dense -0.55 . For fine sands with poorly rounded, a little spherical grains the void ratio decreasing to 0.75 and 0.45 accordingly.

Similar dependences are for medium sands with the changing of their grains shape from slightly angular, anisometric to poorly rounded, a little spherical. Influence of roundness and sphericity of sands grains taking into account changes in roughness of their surface from the rough to very weakly rough, on the range of variation of the void ratio in a very loose and dense state was estimated by the generalized morphological index $(\lambda)$ and is shown in Figure 2.

Analyzing the experimental results, it can be noted that the presence of untreated grains of sand (II category on $\lambda$ ) increase the range of the void ratio variation from $e_{L}$ to $e_{d}$, equal to 0.4. With the increasing of treated of grains (to a category IV on $\lambda$ ) the range between $\mathrm{e}_{\mathrm{L}}$ and $\mathrm{e}_{\mathrm{d}}$ reduces to 0.3 for medium sand and to 0.35 for fine sand. Installed in GOST 251002011 [11] the boundary values of the void ratio ( 0.55 and 0.70 for a medium sand, and 0.60 and 0.75 for a fine sand), as mentioned above, does not take into account the complex of significant factors (grain-size uniformity, the content of fine-grained fractions, mineral composition, hardening of sand, etc.), including morphological features of grains. As shown in Figure 2, this could lead to an incorrect assessment of the relative density of sand. For assessing the relative density of sands in a view of the morphological features of their grains curves of the boundary values of the void ratio, in our opinion, should be parallel in loose and dense state.

The study of the influence of morphology of alluvial sands (fine and medium ) on their density showed that with increasing rates of roundness $(\alpha)$, sphericity $(\beta)$ and generalized morphological index $(\lambda)$, which takes into account the surface roughness of the grains, the density of sand increases and the void ratio decreases.

The content of fraction less than $0.1 \mathrm{~mm}$ in the sands effects the particle size distribution. Thus, the change in a content of this fraction in a fine sand from $1 \%$ to $10.5 \%$ causes a change of the uniformity coefficient in range from 3.1 to 1.8 , and in medium sand with less range of the change of a content of fraction $<0.1 \mathrm{~mm}$ from $0.5 \%$ to $7.5 \%$ a change 
of the uniformity coefficient values from 3.2 to 1.8 . Thus, the influence of the changes in a content of fine fraction of sand on the uniformity coefficient more significantly manifested in medium sands. Non-uniform sands are able to condense more than uniform. Thus (if not take into account the age-hardening of sands), it can be argued that the sands density and the corresponding value of penetration parameters depends on the grain-size of sands, content of the fraction less than $0.1 \mathrm{~mm}$ and morphological features typical for the relevant genetic types of sand.

a)

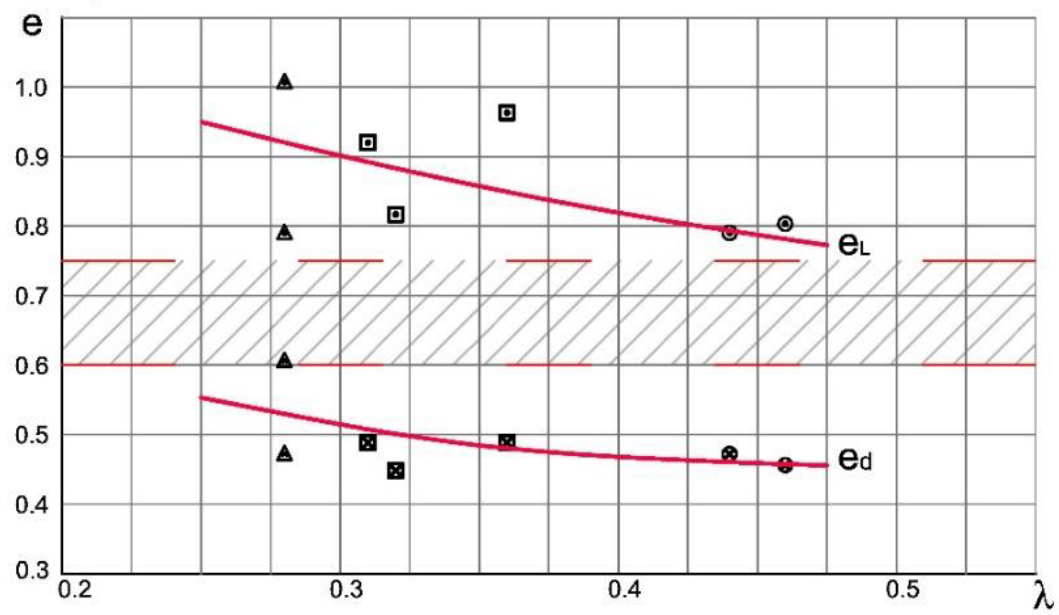

\begin{tabular}{|c|c|c|c|c|}
\hline I & II & III & IV & V \\
\hline
\end{tabular}

$\Delta-$ II $\square-$ III $0-$ IV

b)
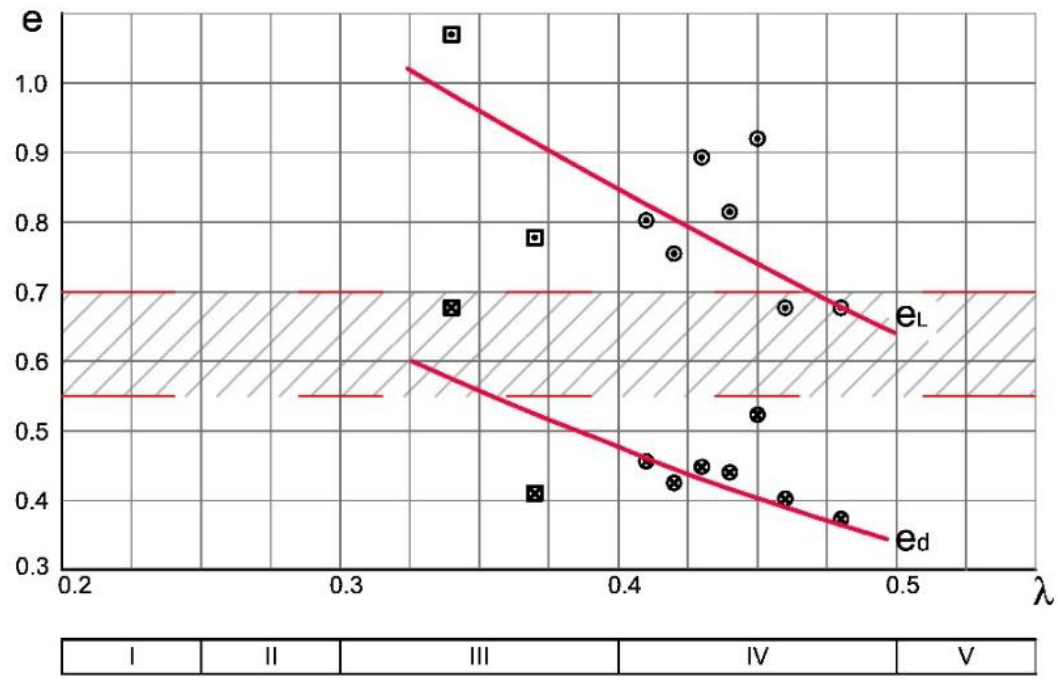

ロ- III 0 - IV

Fig.2. The influence of the generalized morphological index on density of fine (a) and medium (b) sands. Categories of the treatment of grains: I-very rough, II-raw, III-almost raw, IV-soft raw, Vtreated (the values of correlation coefficients vary from 0.74 to 0.94 ). The shaded area on the graphs the values of medium density sands (according to GOST). 
To quantify the density of sandy soils according to the data of cone penetration test was proposed a number of empirical relationships [8, 12, 13, and 14]. In particular, L.G. Mariupolskiy [12] recommends to determine the density of sand from the values of the solid particles density $\left(\rho_{\mathrm{s}}\right)$, moisture weight $(\mathrm{W})$ and a cone resistance $\left(\mathrm{q}_{\mathrm{s}}\right)$ using the following equation:

where $\mathrm{q}_{\mathrm{s}}{ }^{0}=1 \mathrm{MPa}$.

$$
\rho_{d}=\frac{\rho_{s}}{1.765-0.185 \lg \left(\frac{q_{S}}{q_{s}^{0}}\right)}
$$

In our view, recommended equation (1) can be used only for variety of sands averaged by size, without taking into account their uniformity coefficient, genetic affiliation, water saturation, hardening and generalized morphological index.

To verify the correctness of our arguments, results of the cone penetration test (according to the materials of long-term surveys LLC NPF "SIVS", LLC "Investroy", LLC "IGC" in Moscow and the near suburbs) in water-saturated sands (silt, fine and mediumsize) of two genetic types: alluvial (a) and fluvioglacial (f), were analyzed. A comparison of the values of cone resistance $\left(\mathrm{q}_{\mathrm{s}}\right)$ with the values of dry soil density $\left(\rho_{\mathrm{d}}\right)$ in a view of their origin and size shown in Figure 3 (a, b, c).

a)

- $f$ - fluvioglacial

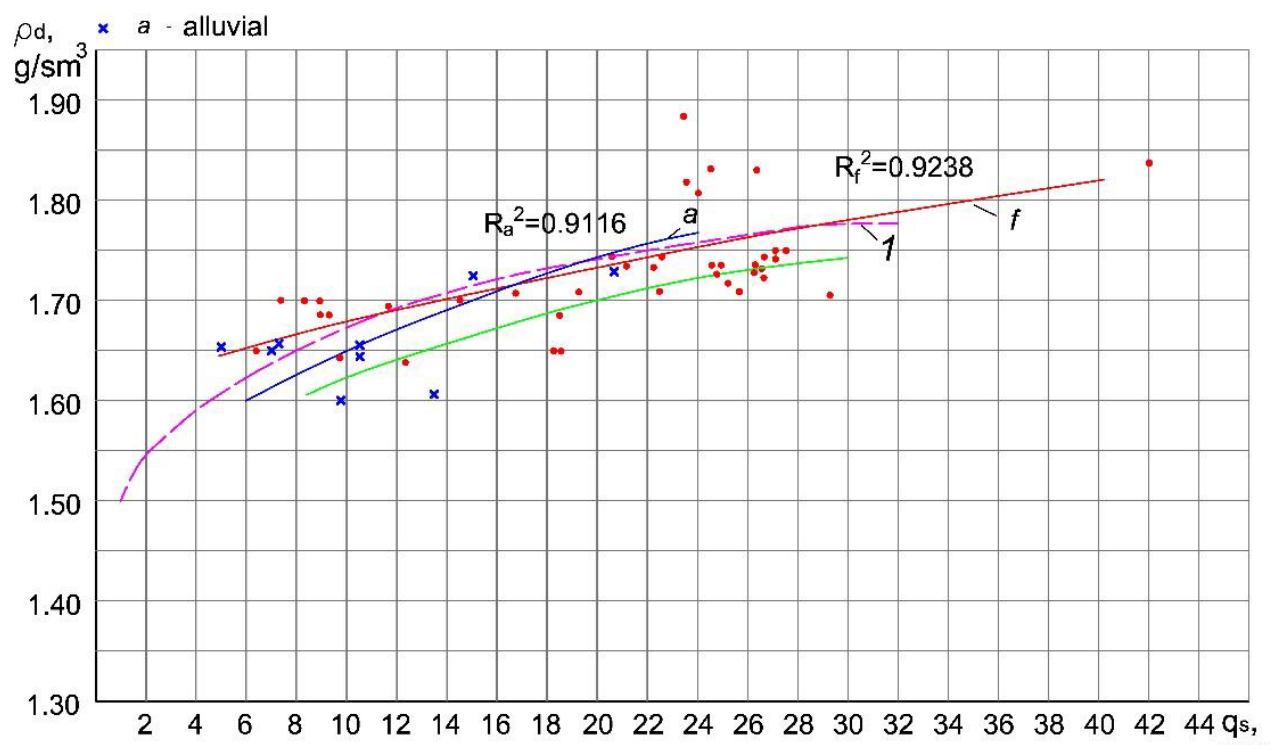

$\mathrm{MPa}$ 
b)

- $f$ - fluvioglacial

$\rho d, \quad \times a-$ alluvial

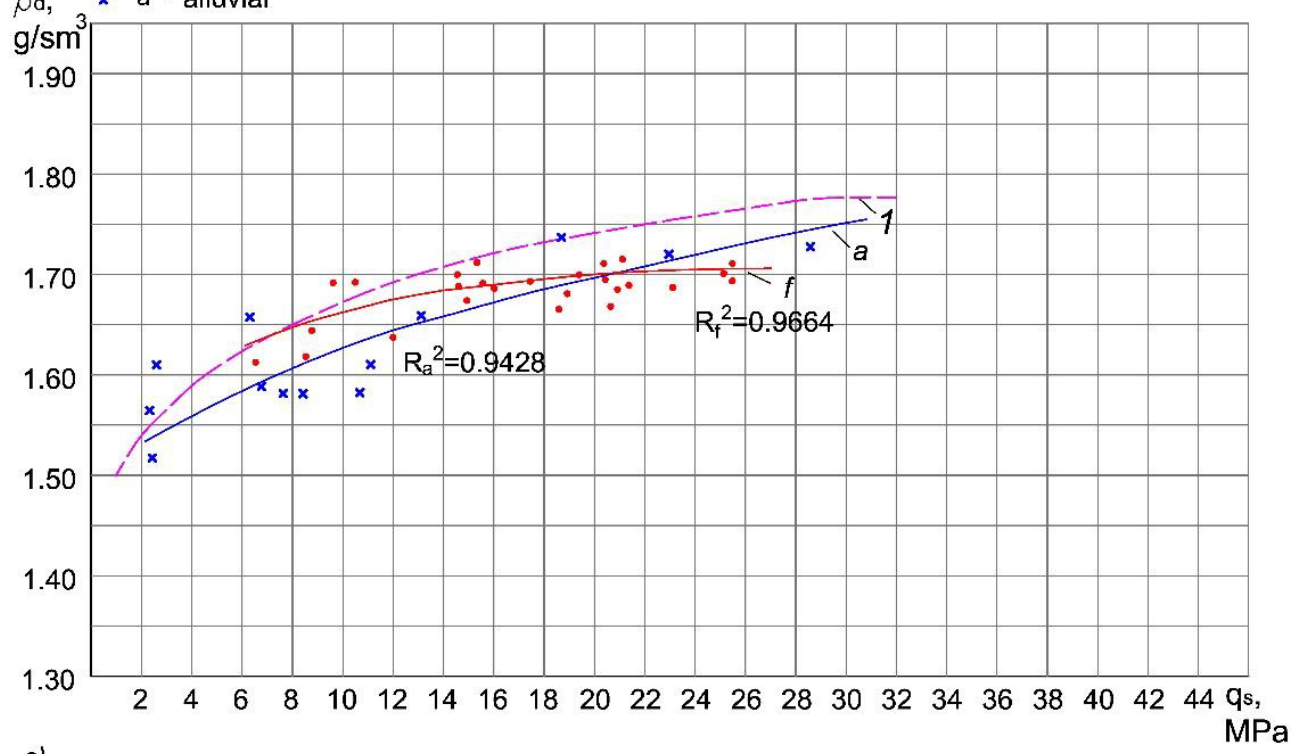

c)

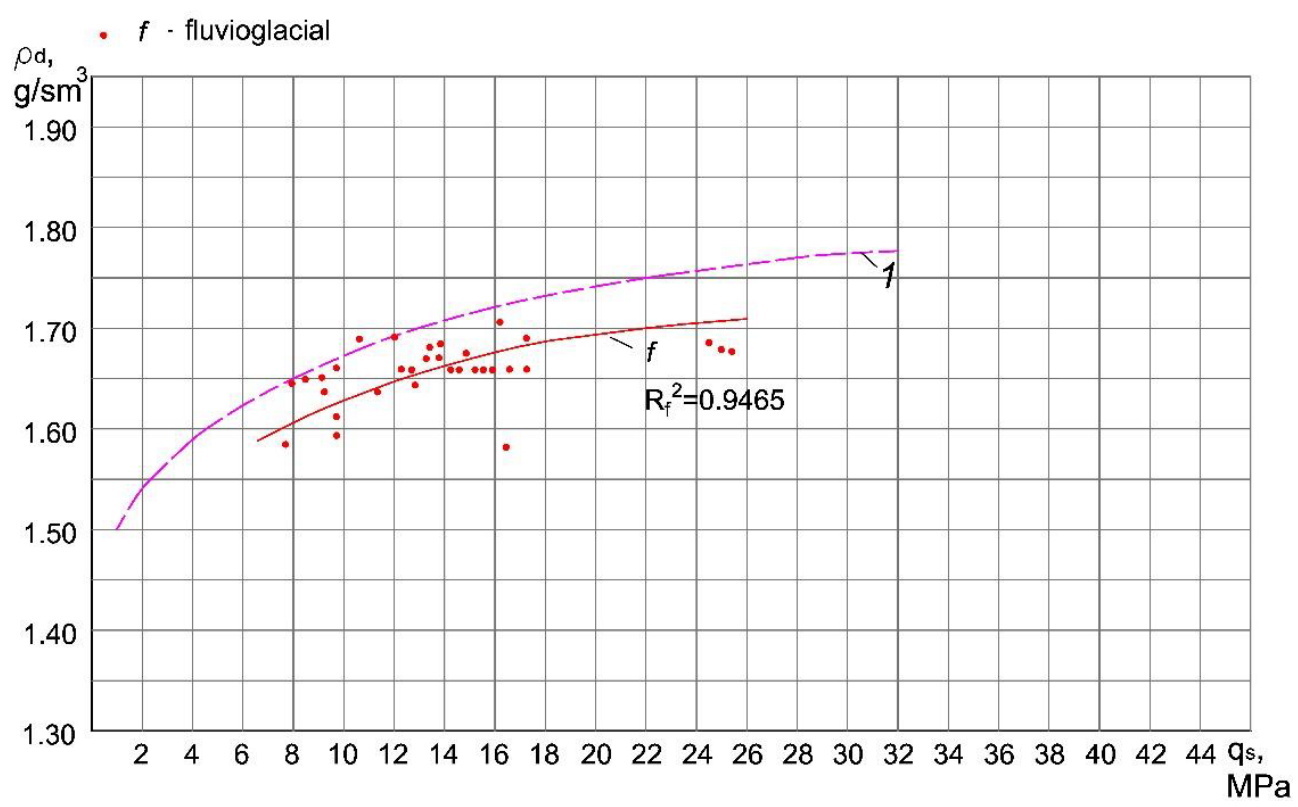

Fig.3. Relationship between dry soil density and cone resistance for water-saturated medium (a), fine (b) and silt (c) sands: alluvial (a) and fluvioglacial (f). 1 - theoretical curve by L.G. Mariupolskiy [12].

Figure $3(a, b, c)$ shows, that the same values of cone resistance of different size sands correspond to different values of the dry soil density. Thus, the finer sand, the lower the absolute value of dry soil density and more differences with their theoretical curve. For each studied species of sands grain-size was evaluated the effect of the morphology of the sand grains on their density. According to the data performed above (Fig. 2) the more 
treated grains fit tighter, that confirmed by a graph of the relationship between dry soil density and cone resistance for the studied genetic types and varieties of grain-size sands (Fig. 3). The scatter of the experimental points explains with the difficulty of the undisturbed sampling of sand in water-saturated state, as well as changes in their morphological parameters that affect the sands density, although not in a large range, even for the same genetic type. In addition, we did not take into account the uniformity coefficient of sand. Thus, it becomes evidence that for the determining the density of quaternary sands necessary to consider their grain-size, uniformity, structural-textural features (hardening), morphological parameters.

Established correlations between the dry soil density of the studied sands and the cone resistance describes by equations shown in the Table 1 . Data are given according to the range of change of cone resistance from $6.0 \mathrm{MPa}$ to $26.0 \mathrm{MPa}$.

Table 1. Correlations between dry sands density and cone resistance, obtained on the basis of the empirical formula L. G. Mariupolskiy (for the quaternary sands of Moscow).

\begin{tabular}{|c|c|c|}
\hline \multirow{2}{*}{ Grain size } & \multicolumn{2}{|c|}{ Genetic type of sand } \\
\cline { 2 - 3 } & $\rho_{d}=\frac{\rho_{s}}{1.765-0.170 \lg \left(\frac{q_{s}}{q_{s}^{0}}\right)}$ & $\rho_{d}=\frac{\rho_{s}}{1.765-0.190 \lg \left(\frac{q_{s}}{q_{s}^{0}}\right)}$ \\
\hline Medium & $\rho_{d}=\frac{\rho_{s}}{1.765-0.142 \lg \left(\frac{q_{s}}{q_{s}^{0}}\right)}$ & $\rho_{d}=\frac{\rho_{s}}{1.765-0.168 \lg \left(\frac{q_{s}}{q_{s}^{0}}\right)}$ \\
\hline Fine & - & $\rho_{d}=\frac{\rho_{s}}{1.765-0.140 \lg \left(\frac{q_{s}}{q_{s}^{0}}\right)}$ \\
\hline Silt & & \\
\hline
\end{tabular}

\section{Summary}

1. Establishing the value of the sands density is an important practical task during the engineering surveys, but very difficult to solve because of the difficulty of undisturbed sampling, especially in water-saturated sands. The established categories of sands density by cone resistance $\left(\mathrm{q}_{\mathrm{s}}\right)$ provide only a qualitative picture on sands density. Proposed earlier dependence (by L.G. Mariupolskiy) to quantifying the density of sand in terms of the cone resistance does not take into account a number of factors that influence the formation of the sands density, which leads in some cases to large differences in the density values identified by direct and indirect methods.

2. To improve the accuracy of determining the sands density is important to consider not only their particle size distribution (the size and uniformity), hardening of the soil due to the formation of structural links, but also the genesis of the sands, which determines the morphological features of the sands grains.

3. For each variety of sand (by particle size and uniformity) is necessary to install the morphological characteristics of their grains, for what the generalized morphological index $\lambda$ (proposed by A.D. Potapov) can be used. These works will allow to make a series of correlations at sites, to describe them with the equations and use in the engineering surveys for quantifying the sands density.

4. It should be noted that such an approach to the determination of the sands density by cone penetration test valid for quaternary sediments in which virtually no cementitious hardening of sand, except highly ferruginized differences. In assessing the density of pre- 
quaternary sands should be taken into account also the presence of clay and silt layers, sections, cemented siliceous phosphate cement, which will have an additional impact to cone penetration, increasing the value of cone resistance. As a result, for the same size sands will be formed their own correlations on their density and cone resistance because of the differences in their structural and textural features inherent for sediments of different ages.

\section{References}

1. SP 47. 13330. 2012. Engineering surveys for construction, Moscow (2013)

2. Genesis and model of the formation of soil properties/ Edited by V. T. Trofimov and V. A. Korolev, M.: Publisher MSU, 165 (1998)

3. I. V. Dudler, A. D. Potapov, A. N. Yulin. Some features of the grains of sand of different origins and methods of their study. Collection of Engineering Geology, №111, Moscow, MISI, 109-123 (1974)

4. P. L. Ivanov, L. V. Shulc. Influence of particle shape on the properties of alluvial sands facilities. Hydraulic Engineering, №11, Moscow, 47-49 (1972)

5. A. D. Potapov. Morphological study of sands in geotechnical purposes. Autoabstract, Moscow, 24 (1982)

6. Recommendations for the integrated study and evaluation of building properties of sandy soils. M.: Stroyizdat, 212 (1984)

7. V. T. Trofimov, V. A. Korolev, E. A. Voznesenskiy, G. A. Golodkovskaya, Yu. K. Vasilchuk, R. S. Ziangirov. Soil sciencel Edited by V. T. Trofimov. M.: Publisher MSU, 1024 (2005)

8. Yu. G. Trofimenkov, L. N. Vorobkov. Field research methods of construction properties of soils. M.: Stroyizdat, 215 (1981)

9. V. I. Kashirskiy. Methods of studying the composition and properties of fine-grained soils by field methods in a metropolis (on the example of Moscow). Autoabstract. Moscow (2005)

10. A. D. Potapov Method of rapid determination of the morphology of the grains of sand with different genesis. Deposited manuscript VINITI, №10-76, Moscow (1975)

11. GOST 25100-2011. Soils. Classification. Moscow (2013)

12. L. G. Mariupolskiy. Soil analysis for the design and construction of pile foundations. M, Стройиздат, 199 (1989)

13. BS 5930-1999. Code of practice for site investigations.

14. T. Lunne, P. K. Robertson, J. J. M. Powel. Cone Penetration Testing in geotechnical practice, 312 (1997) 